\title{
State of Shock: Epidemiological, Etiological and Therapeutic Aspects at the Pediatric Unit of the Medical and Surgical Emergencies of the Donka National Hospital
}

\author{
Diallo Mohamed Lamine ${ }^{1}$, Barry Ibrahima Koolo², Camara Emmanuel ${ }^{3}$, \\ Ondima Hermann Laurent Marion ${ }^{2}$, Sossouadouno Elisabeth Sita ${ }^{1}$, Diallo Saliou Bella ${ }^{3}$ \\ ${ }^{1}$ Emergencies Pediatric, Donka National Hospital, Conakry, Guinea \\ ${ }^{2}$ Institute of Nutrition and Child Health (INSE), Donka National Hospital, Conakry, Guinea \\ ${ }^{3}$ Pediatric Department, Donka National Hospital, Conakry, Guinea \\ Email: *laminemacky@yahoo.fr, kholobarry@gmail.com,dremmano74@gmail.com, hermannondima@yahoo.fr, \\ Elisabethtouro@gmail.com,mdoulamarana@gmail.com
}

How to cite this paper: Lamine, D.M., Koolo, B.I., Emmanuel, C., Marion, O.H.L., Sita, S.E. and Bella, D.S. (2019) State of Shock: Epidemiological, Etiological and Therapeutic Aspects at the Pediatric Unit of the Medical and Surgical Emergencies of the Donka National Hospital. Open Journal of Pediatrics, 9, 302-308.

https://doi.org/10.4236/ojped.2019.94029

Received: February 2, 2019

Accepted: November 24, 2019

Published: November 27, 2019

Copyright $\odot 2019$ by author(s) and Scientific Research Publishing Inc. This work is licensed under the Creative Commons Attribution International License (CC BY 4.0).

http://creativecommons.org/licenses/by/4.0/

Open Access

\begin{abstract}
Introduction: The objective of this study was to write the epidemiological, etiological and therapeutic aspects of shock in children in the paediatric medico-surgical emergency unit of the National Donka Hospital. Method: This was a forward-looking, descriptive 6-month study, including all children aged 0 to 15 who were received in the paediatric medico-surgical emergency unit at The Donka National Hospital, where the shock diagnosis was retained and the patients received care. Results: In our study, 26 out of 1123 patients were received in a state of shock. Hypovolemic shock was more common at 24 (92\%). Vascular filling by Ringer's milk was the basic treatment. The 6 to 11 month age group was the most affected and the sex-ratio M/F was 1.6. The acute febrile gastroenteritis and dehydration status were the most frequent causes. The outcome was favorable in 25 patients (96\%). Conclusion: Rapid and effective management would improve the vital and functional prognosis of children in shock.
\end{abstract}

\section{Keywords}

Choc, Children, Urgences, Paediatrics, Donka

\section{Introduction}

Shock is a vital emergency due to acute circulatory insufficiency characterized by 
inadequate supply and oxygen requirements. It can result either from a decrease in the oxygen supply, or from a lack of oxygen utilization by the cell, or from a combination of both [1] [2].

Several etiologies can be at the origin of a state of shock. However, regardless of the etiology and mechanism of this state of shock, it is characterized by hypo-infusion or inadequate tissue perfusion with hypoxia, or even cellular anoxia, resulting in the metabolism of the aerobic pathway to the body anaerobic pathway with a defect in the production of adenosine triphosphate, the main energy source of the cell [2].

In the United-States, a survey by Watson found an incidence [3] of 0.56 cases per 1000 children per year and an e-hospital mortality rate of $10 \%$ which corresponded to 6 deaths per 100,000 children under 18 years a year. Among the causes of death, severe sepsis accounted for $7 \%$ of cases, a value well above cancer-related mortality [3] [4].

In Western Europe and North America, hemorrhagic shock is the most common cause among other shock conditions in children [5]; in France the hypovolemic shock is the first cause of shock in the child among other states of shock [6].

In sub-Saharan Africa, specifically in Senegal, the prevalence of shock among hospitalized newborns is $9 \%$ [7].

The state of shock is a vital emergency; its diagnosis is based solely on the clinic. The identification of nature is based on a group of essentially anamnestic and clinical arguments. The para-clinical examinations provide only additional information to clarify the mechanism [2]. The efficiency of treatment depends on rapid recognition of the judgment and the triggering factor was taken into etiological load. Therapeutic delay is a risk factor for poor prognosis [5] [7].

The aim of this study was to write epidemiological, aetiological and therapeutic aspects of the state of shock in children at the pediatric unit of the medical-surgical emergencies of Donka National Hospital.

\section{Method}

This is a transversal, prospective type descriptive six months, from March 9 to September 9, 2015. We included all children aged 0 to $s 15$ years in which the diagnosis of shock has was retained and treated at the pediatric unit of the medical and surgical departments of the National Donka Hospital during the period.

The epidemiological data (age, gender), clinical (reasons for consultation, physical signs, diagnosis) etiological (hypovolemic shock, or septic shock) and therapeutic (drugs) were studied. Informed consent was obtained from any parent of the patient before inclusion of the patient in the study.

Have been defined as cases of shock, any patient with Tachycardia, TRC $>3$ seconds, a small pulse or shooting, hypothermia, cold extremities, agitation, respiratory distress, Hypoxia, Oliguria. 
The research was conducted according to the principles of the Helsinski Declaration.

\section{Results}

We collected 26 cases of shock on 1123 children admitted to consultation during the study (2.3\%), including 16 boys (61.54\%), 10 girls (38.46\%) and a sex ratio. $\mathrm{M} / \mathrm{F}$ of 1.6. The average age was 33 months with extremes of 5 and 180 months (Tables 1-3).

24 cases (92\%) of hypovolemic shock were recorded against 2 cases (8\%) of septic shock.

We recorded 24 cases (2\%) of acute febrile gastroenteritis with dehydration associated with severe malaria and meningitis; 1 case (4\%) of haemorrhage due to open collarbone fracture with frontal wound and 1 case (4\%) of septicemia due to abscess of the right thigh with anal wound.

Among the emergency checkups, a blood glucose, a hemoglobin level, a thick drop with parasite density, a TDR and white blood cells were realized in cases (100\%); Lumbar puncture in 11 cases (42\%) and blood grouping/Rh factor in 1 case (4\%) (Table 4).

Table 1. Breakdown of 26 patients in a state of shock based on epidemiological characteristics in the Pediatric Unit of the National Donka Hospital.

\begin{tabular}{|c|c|c|}
\hline Characteristics & $\mathbf{n}$ & $\%$ \\
\hline \multicolumn{3}{|c|}{ Age group (months) } \\
\hline $0-5$ & 7 & 27 \\
\hline $6-11$ & 12 & 46 \\
\hline $12-23$ & 0 & 0 \\
\hline $24-59$ & 4 & 15 \\
\hline $60-119$ & 1 & 4 \\
\hline $120-180$ & 2 & 8 \\
\hline \multicolumn{3}{|c|}{ Reasons for consultation } \\
\hline Vomiting & 23 & 88 \\
\hline Fever & 21 & 81 \\
\hline Diarrhea & 18 & 69 \\
\hline Sweats & 3 & 12 \\
\hline Agitations & 2 & 8 \\
\hline Loss of consciousness & 2 & 8 \\
\hline Bleeding & 2 & 8 \\
\hline Inability to suck & 2 & 8 \\
\hline Respiratory distress & 1 & 4 \\
\hline
\end{tabular}


Table 2. Frequency of clinical signs in 26 patients in shock in the Pediatric Unit of hospital National Donka.

\begin{tabular}{|c|c|c|}
\hline Clinical signs & $\mathbf{n}$ & $\%$ \\
\hline \multicolumn{3}{|c|}{ Cardiovascular } \\
\hline Tachycardia & 20 & 77 \\
\hline Bradycardia & 17 & 65 \\
\hline TRC Peripheral $>3 \mathrm{~s}$ & 16 & 62 \\
\hline Running pulses & 14 & 54 \\
\hline Small pulse & 11 & 42 \\
\hline Cold end & 4 & 15 \\
\hline Cyanosis & 1 & 4 \\
\hline \multicolumn{3}{|c|}{ Neurological } \\
\hline Obnubilation & 12 & 46 \\
\hline Coma & 4 & 15 \\
\hline Agitation & 3 & 12 \\
\hline Drowsiness & 1 & 4 \\
\hline \multicolumn{3}{|c|}{ Respiratory } \\
\hline Polypnoea Respiratory distress & 15 & 58 \\
\hline Polypnoea Kespiratory aistress & 10 & 38 \\
\hline Bradypnea & 6 & 23 \\
\hline Hypoxia & 5 & 19 \\
\hline \multicolumn{3}{|c|}{ Urinary, cutaneous and general } \\
\hline Oliguria & 9 & 35 \\
\hline Hyperthermia & 21 & 81 \\
\hline Hypothermia & 1 & 4 \\
\hline Dryness of the mucous membranes & 22 & 85 \\
\hline Pallor & 7 & 27 \\
\hline
\end{tabular}

Table 3. Distribution of the 26 patients by age according to the pathologies encountered in the paediatric unit of the National Donka hospital.

\begin{tabular}{cccccc}
\hline Age (month) & Malaria Serious & Meningitis & Open fracture & Septicemia & Total \\
\hline $0-5$ & 0 & 7 & 0 & 0 & 7 \\
$6-11$ & 8 & 4 & 0 & 0 & 12 \\
$12-23$ & 0 & 0 & 0 & 0 & 0 \\
$24-59$ & 3 & 0 & 0 & 0 & 3 \\
$60-119$ & 1 & 0 & 0 & 0 & 1 \\
$120-180$ & 1 & 0 & 1 & 1 & 3 \\
Total & 13 & 11 & 1 & 1 & 26 \\
\hline
\end{tabular}


Table 4. Distribution of 26 patients undergoing treatment in the pediatric unit of the National Donka Hospital.

\begin{tabular}{ccc}
\hline Treatment & Effective & Percentage \\
\hline Lactated Ringer & 26 & 100 \\
Saline serum & 2 & 8 \\
Haemaccel & 2 & 8 \\
Transfusion & 1 & 4 \\
Paracetamol & 21 & 81 \\
Vogalène & 16 & 62 \\
Ceftriaxone & 9 & 35 \\
Ampicillin & 5 & 19 \\
Dexamétazone & 5 & 19 \\
Diazepam & 3 & 12 \\
Metronidazole & 1 & 4 \\
\hline
\end{tabular}

Two (02) patients were transferred respectively to pediatric and trauma services for adapted care after managing the medical emergency (vascular filling, antipyretic perfusable, antiemetic, antibiotic and corticosteroid).

\section{Discussion}

The weakness of equipments of the technical platform, and the non-realization of certain para-clinical investigations (ionogram and blood gasometry) were limits to the study without compromising the results.

From 09 March to 09 September 2015, we carried out a prospective cross-sectional study of the descriptive type at the pediatric unit of the medical and surgical departments of the National Donka Hospital on the state of shock of the child. It represented $2.3 \%$ of consultations of this period. This low result could be explained by the epidemic of Ebola virus disease that erupted during this period, leading to a decline in patient attendance in the service. The 6 to 11 month age group was the most affected followed by the 0 to 5 month age group. Our results are similar to those of Touzani [1] in 2010 in Morocco who found that the $2-10$ month period was the most affected.

In addition, vomiting, fever and diarrhea were common reasons for consultation. These same causes were also mentioned by Nada [8] and Touzani [1] in their studies. $\mathrm{T}$ his finding may explain the vulnerability of our patients (children under 15) face this triad POUVA cause severe water loss leading to dehydration and hypovolemic shock.

Tachycardia, TRC $>3 \mathrm{~s}$, pulse rate, obstruction, polypnea and fever were the most common signs of shock in this study. This observation, similar to the suggestive signs reported by literature data [9], is explained by the causal mechanism of shock. 
Among the types of shock encountered in this study, hypovolemic shock was by far the most represented. This observation is explained by the presence of absolute hypovolemia in the majority of our patients due to digestive losses reported at the time of admission (diarrhea, vomiting).

The treatment was based first on the vascular filling and this was done mainly with Ringer Lactate. This conduct is similar to that stated in the Nada [8], Paut [1] and Soummer [2]. The predominant use of solute is due to its availability and low cost in our midst.

Ts antipyretic, antiemetic and antibiotic were administered in more than half of patients. This support is superimposable to that of art work Touzani [5] which used in the treatment of patients anti-diarrheal them (77\%), anti-emetics (61\%) and antibiotics (13.8\%). This would be explained in our context by the prevalence of fever and vomiting in our patients.

\section{Conclusions}

The shock is a medical emergency which is a frequent reason for admission in pediatrics and intensive care. The diagnosis is essentially clinical.

The treatment is based on vascular filling with solutes, antibiotic therapy, corticosteroid therapy, analgesics, antiemetics.

The quick and effective support would improve the vital and functional prognosis of children in shock.

\section{Conflicts of Interest}

The authors declare no conflicts of interest regarding the publication of this paper.

\section{References}

[1] Nada Tazi, E.P. (2011) The Practical Guide of the Main Pediatric Emergencies CHU Hassan II of Fès [Thesis]. UniversitySidi Mohammed Ben Abdellah, Fez.

[2] Paut, O., Ughetto, F. and Labenne, M. (2010) Pediatric Peculiarities of the State of Shock. Refresh Conferences, 52nd National Congress of Anesthesia and Resuscitation Doctors, 1-50.

[3] Watson, R.S., Carcillo, J.A. and Linde-Zwirble, W.T. (2003) The Epidemiology of Severe Sepsis in Children in the United States. American Journal of Respiratory and Critical Care Medicine, 167, 695-701. https://doi.org/10.1164/rccm.200207-682OC

[4] Orliaguet, G., Gauvin, F., Hume, H., Lacroix, J., et al. (2007) Haemorrhagic Shock. In: Emergency and Pediatric Intensive Care, CHU Sainte-Justine and Elsevier-Masson, Montreal, 167-186.

[5] Touzani, F. (2010) Acute Gastroenteritis Rotavirus in Infants (About 42 Cases) [Thesis]. Sidi Mohammed Ben Abdellah University, Fès.

[6] Faye, B.F., Sylla, A., Seck, M., Sall, A., et al. (2013) Diagnostic and Evolutionary Aspects of Haemorrhagic Syndromes of the Newborn in Dakar. Pediatric Archive, 20, 164-170. https://doi.org/10.1016/j.arcped.2012.11.010

[7] Boot, A. and Leclerc, F. (2009) Initial Management of Shock in Children. Emergency Medicine, 31, 361-372. 
[8] Coste, Ph., Dumont, R., Benatia, P., Allal, H., et al. (2006) Shock Hypovolé Nomic by Lower Gastrointestinal Bleeding in an Infant. Emergency Medicine, 28, 113-116.

[9] Watson, R.S. and Carcillo, J.A. (2005) Scope and Epidemiology of Pediatric Sepsis. Pediatric Critical Care Medicine, 6, 3-5.

https://doi.org/10.1097/01.PCC.0000161289.22464.C3 